\title{
Microscopic Findings Original Result
}

National Cancer Institute

\section{Source}

National Cancer Institute. Microscopic Findings Original Result. NCI Thesaurus. Code C117582.

The outcome of the microscopic assessment as originally received or collected. 